\title{
Perioperative hemoglobin decrement as an independent risk of poor early graft function in kidney transplantation
}

\author{
Arpa Chutipongtanate ${ }^{1}$, Arpakorn Kantain ${ }^{1}$, Atiporn Inksathit ${ }^{2}$, Surasak Kantachuvesiri ${ }^{3,4,5}$, Vasant Sumethkul ${ }^{3}$, \\ Siriwan Jirasiritham ${ }^{1}$, Sopon Jirasiritham ${ }^{4,5}$ and Somchai Chutipongtanate ${ }^{2,6^{*}}$ (D)
}

\begin{abstract}
Objective: Perioperative change of hemoglobin concentration $(\mathrm{Hb})$ was associated with acute kidney injury in patients who underwent non-cardiac surgery, but has never been investigated in kidney transplant patients. This study aimed to observe the effects of perioperative $\mathrm{Hb}$ change on early graft function in kidney transplant recipients.

Results: A total of 269 kidney transplant patients were enrolled, of whom 98 (36.4\%) developed poor early graft function (PEGF), and 171 (63.6\%) had immediate graft function. Comparing two groups, patients with PEGF had a greater decremental change of $\mathrm{Hb}(-1.60[-2.38,-0.83]$ vs. $-0.70[-1.35,0.20] \mathrm{g} / \mathrm{dL}$, respectively; $p<0.001)$. A Hb cut-point of $-1.35 \mathrm{~g} / \mathrm{dL}$ was obtained from ROC analysis. Multivariate analysis showed that perioperative $\mathrm{Hb}$ decrement greater than $1.35 \mathrm{~g} / \mathrm{dL}$ was an independent risk of PEGF (adjusted OR of 2.52, $95 \% \mathrm{Cl} 1.11-5.72 ; p=0.026$ ). Subgroup analysis revealed deceased donor kidney transplant (DDKT; $\mathrm{n}=126$ ) (adjusted OR of 2.89, 95\% $\mathrm{Cl} 1.11-7.55 ; p=0.029$ ), but not living donor kidney transplantation ( $L D K T ; n=143$ ) (adjusted OR of $1.68,95 \% \mathrm{Cl} 0.23-12.15 ; p=0.606$ ), was influenced by the perioperative $\mathrm{Hb}$ decrement. In conclusion, this study suggests that decremental change in perioperative $\mathrm{Hb}$ greater than $1.35 \mathrm{~g} / \mathrm{dL}$ may serve as a modifiable factor of PEGF in DDKT.
\end{abstract}

Keywords: Hemoglobin, Kidney transplantation, Perioperative medicine, Poor early graft function

\section{Introduction}

Quality of early graft function in kidney transplant patients is an important predictor for long-term graft outcome. Early graft function can be divided into delayed graft function (DGF), slow graft function (SGF), and immediate graft function (IGF). The incidence of DGF varies between 10 and $54.2 \%$, and is associated with an increased risk of acute rejection and subsequent poor long-term graft survival [1-7]. However, its definition is not consistent, leading to conflicting data $[6,8]$. Slow

\footnotetext{
*Correspondence: schuti.rama@gmail.com; somchai.chu@mahidol.edu ${ }^{6}$ Pediatric Translational Research Unit, Department of Pediatrics, Faculty of Medicine Ramathibodi Hospital, Mahidol University, 270 Rama VI Rd, Ratchathewi, Bangkok 10400, Thailand

Full list of author information is available at the end of the article
}

graft function (SGF) is defined as an intermediate condition between DGF and IGF $[9,10]$, and represents part of the spectrum of graft injury [10]. Patients with SGF also had poorer long-term graft outcome than patients with IGF [9-11]. Since both SGF and DGF determined a similarly negative impact on patient and graft survival [10-12], poor early graft function (PEGF) that covered the overall spectrum of graft dysfunction has been initially applied when evaluating the significance of early graft function [12, 13]. Long-term graft survival, acute rejection-free survival, and 1-year renal function in living donor kidney transplant patients who developed PEGF were significantly lower than those with IGF [12-14].

Risk factors of PEGF have still been under investigation. Factors being associated with PEGF were recipients BMI, pre-transplant dialysis, advanced donor age, and

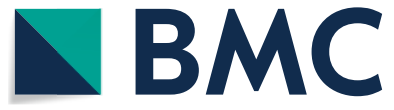

(c) The Author(s) 2020. This article is licensed under a Creative Commons Attribution 4.0 International License, which permits use, sharing, adaptation, distribution and reproduction in any medium or format, as long as you give appropriate credit to the original author(s) and the source, provide a link to the Creative Commons licence, and indicate if changes were made. The images or other third party material in this article are included in the article's Creative Commons licence, unless indicated otherwise in a credit line to the material. If material is not included in the article's Creative Commons licence and your intended use is not permitted by statutory regulation or exceeds the permitted use, you will need to obtain permission directly from the copyright holder. To view a copy of this licence, visit http://creativeco mmons.org/licenses/by/4.0/. The Creative Commons Public Domain Dedication waiver (http://creativecommons.org/publicdomain/ zero/1.0/) applies to the data made available in this article, unless otherwise stated in a credit line to the data. 
prolonged warm ischemic time (WIT) [12-14]. Since DGF is a subset of PEGF, risk factors such as deceased donor type, prolonged cold ischemic time (CIT), higher rate of HLA mismatch, and/or higher panel reactive antibody level (PRA) [2-4, 15], may also contribute to PEGF. It is desirable identifying modifiable factors of PEGF as a measure to improve long-term graft outcomes.

We hypothesized that perioperative change in $\mathrm{Hb}$ may serve as a modifiable risk factor of PEGF. Two lines of evidence supported this hypothesis. First, Abou-Jaoude et al., reported that pre-operative hemoglobin levels, either too high or too low, both affected early and longterm graft outcomes in kidney transplant patients [16]. Second, Walsh et al., demonstrated that even small decrements in perioperative hemoglobin concentration were strongly associated with acute kidney injury in non-cardiac surgical patients with normal pre-operative renal function [17]. Therefore, patients with kidney transplant should be even more vulnerable to changes of hemoglobin levels during the perioperative period, and acute kidney injury would manifest as poor early graft function in this context.

The aim of this study was to investigate perioperative $\mathrm{Hb}$ change in patients with PEGF as compared to IGF. The association between PEGF and perioperative $\mathrm{Hb}$ change was further analysed by univariate and multivariate analyses. Other variables were also systematically evaluated to identify the additional risk of PEGF.

\section{Main text Methods \\ Sample population}

This study was approved by the Ethical Clearance Committee on Human Right Related to Research involving Human Subjects, Faculty of Medicine Ramathibodi Hospital, Mahidol University (Protocol ID 03-5739). Informed consent was waived because of retrospective nature of the study. Patient information was anonymized and de-identified before analysis. Data were retrospectively collected from medical records of patients $\geq 18$ years of age who underwent first kidney transplant at Ramathibodi Hospital, Thailand, during January 1, 2011 and December 31, 2013. Requirements were at least 1 pre and 1 post-operative hemoglobin measurement within 24-h of surgery; patients with post-operative acute rejection were excluded. Demographic data were recorded as shown in Table 1 . The reason and common conditions of deceased donors included brain death due to traffic-related trauma (52\%), cerebrovascular accident (31\%), fall and other trauma (10\%), and other causes (7\%), i.e., cardiovascular diseases, primary brain tumors, and asphyxia. All patients received immunosuppressive therapy, including a calcineurin inhibitor (tacrolimus or cyclosporine), antiproliferative agents (mycophenolate mofetil or azathioprine) and prednisolone.

\section{Definitions}

IGF was defined as a serum creatinine $<3 \mathrm{mg} / \mathrm{dL}$ on postoperative day 5 [12]. SGF was defined as a serum creatinine $\geq 3 \mathrm{mg} / \mathrm{dL}$ on postoperative day 5 without the need of dialysis during the first postoperative week [12]. DGF was defined as the need for dialysis within the first postoperative week, which was the most frequent used definition [6, 12]. PEGF included both DGF and SGF [12-14], thus covered the overall spectrum of graft dysfunction.

\section{Data analysis}

Patients were divided into two groups; those with IGF and those with PEGF, according to the definitions above. The change in perioperative $\mathrm{Hb}$ was calculated by subtracting the last known pre-operative from the lowest within-24-h post-operative $\mathrm{Hb}$. The percentage of $\mathrm{Hb}$ decrement was calculated by $100 *$ [pre-transplant $\mathrm{Hb}$ - postoperative $\mathrm{Hb}$ ]/pre-transplant $\mathrm{Hb}$. To evaluate the association between perioperative $\mathrm{Hb}$ change and PEGF, a cut-point was defined using receiver operating characteristic (ROC) curve. In case sensitivity and specificity needed to be traded off, the cut-point values with $75-80 \%$ specificity were screened to select the value with the best-possible sensitivity and the highest AUC. To identify the other PEGF risk factors, all significant variables from descriptive analysis were included into logistic regression analysis.

\section{Statistical analysis}

Statistical analysis was performed by Excel and R packages. Quantitative data were presented as percentage, proportion, mean $\pm \mathrm{SD}$ or median and interquartile range [IQR] as appropriate. Chi-square or Fischer's exact test were used for categorical variables, while Student's t-test or Mann-Whitney U-tests were used for continuous variables. The confidence intervals of the AUC was calculated by the DeLong method. Univariate and multivariate analysis were used to estimate crude OR and adjusted OR with $95 \%$ CI. $P$-value of $<0.05$ was considered as statistical significance.

\section{Results}

Initially altogether 319 kidney transplant recipients were assessed for eligibility and 280 recipients were included (Additional file 1: Figure S1). Eleven patients were excluded due to acute rejection post-operatively (Additional file 1: Figure S1). Of the remaining 269 patients, 164 were males; mean age was 41.8 years (range 18-63). There were 171 patients with IGF (63.6\%) and 98 patients with PEGF (36.4\%); characteristics of the groups are 
Table 1 Characteristics of recipients, donors and intraoperative variables

\begin{tabular}{|c|c|c|c|}
\hline Variables & PEGF $(n=98)$ & IGF $(n=171)$ & $P$-value \\
\hline \multicolumn{4}{|l|}{ Recipients } \\
\hline Age (year), mean $\pm S D$ & $42.7 \pm 10.8$ & $41.4 \pm 11.7$ & 0.393 \\
\hline Gender, male & $62(63.3)$ & $102(59.6)$ & 0.604 \\
\hline $\mathrm{BMI}\left(\mathrm{kg} / \mathrm{m}^{2}\right)$, mean $\pm \mathrm{SD}$ & $22.4 \pm 4.2$ & $21.6 \pm 3.8$ & 0.087 \\
\hline Comorbid & & & 0.125 \\
\hline Smoking & $20(20.4)$ & $30(17.5)$ & \\
\hline Diabetes mellitus & $5(5.1)$ & $28(16.4)$ & \\
\hline Hypertension & $89(90.8)$ & $155(90.6)$ & \\
\hline Coronary artery disease & $3(3.1)$ & $9(5.3)$ & \\
\hline Cerebrovascular disease & $0(0.0)$ & $2(1.2)$ & \\
\hline Causes of ESRD & & & 0.020 \\
\hline Diabetes mellitus & $2(2.0)$ & $16(9.4)$ & \\
\hline Hypertension & $2(2.0)$ & $2(1.2)$ & \\
\hline Renal diseases & $20(20.4)$ & $70(40.9)$ & \\
\hline Congenital & $1(1.0)$ & $6(3.5)$ & \\
\hline Unknown/others & $70(71.4)$ & $91(53.2)$ & \\
\hline Dialysis modality & & & 0.165 \\
\hline Hemodialysis & $87(88.8)$ & $143(83.6)$ & \\
\hline Peritoneal dialysis & $9(9.2)$ & $21(12.3)$ & \\
\hline Baseline creatinine $(\mathrm{mg} / \mathrm{dL})$, mean $\pm S D$ & $9.48 \pm 3.7$ & $8.18 \pm 3.7$ & 0.007 \\
\hline Baseline pre-transplant hemoglobin ( $/ \mathrm{dL}$ ), median [IQR] & $11.8[10.7,13.2]$ & $11.4[10.1,12.6]$ & 0.700 \\
\hline Postoperative hemoglobin (g/dL), median [IQR] & $10.4[9.4,11.1]$ & $10.6[9.6,11.7]$ & 0.150 \\
\hline Positive anti-CMV & $94 / 95(98.9)$ & $163 / 166(98.2)$ & 0.520 \\
\hline Pretransplant PRA (\%), median [IQR] & $0[0,53]$ & $0[0,0]$ & 0.003 \\
\hline Pretransplant blood transfusion & $31(31.6)$ & $50(29.2)$ & 0.721 \\
\hline \multicolumn{4}{|l|}{ Donors } \\
\hline Age (year), mean $\pm S D$ & $43.9 \pm 14.5$ & $39.0 \pm 11.2$ & 0.002 \\
\hline Gender, male & $76(77.6)$ & $83(48.5)$ & $<0.001$ \\
\hline HLA-A + B + DR mismatch, median [IQR] & $2[2,3]$ & $3[2,4]$ & 0.012 \\
\hline Deceased donor & $87(88.7)$ & $39(22.8)$ & $<0.001$ \\
\hline WIT (min), median [IQR] & $45[38,55]$ & $39[32,50]$ & 0.004 \\
\hline CIT (min), median [IQR] & $1205[909,1378]$ & $27[18,72]$ & $<0.001$ \\
\hline \multicolumn{4}{|l|}{ Intraoperative } \\
\hline Intravenous fluid (L), median [IQR] & $3.6[3.0,4.2]$ & $3.5[2.9,4.1]$ & 0.737 \\
\hline Blood transfusion & $10(10.2)$ & $23(13.5)$ & 0.435 \\
\hline $\mathrm{EBL}(\mathrm{mL})$, median $[\mathrm{IQR}]$ & $400[300,600]$ & $300[200,400]$ & $<0.001$ \\
\hline Need for vasopressor & $21(21.4)$ & $45(26.3)$ & 0.378 \\
\hline \multicolumn{4}{|l|}{ Perioperative } \\
\hline Perioperative $\mathrm{Hb}$ change $(\mathrm{g} / \mathrm{dL})$, median $[\mathrm{IQR}]$ & $-1.6[-2.38,-0.83]$ & $-0.7[-1.35,0.20]$ & $<0.001$ \\
\hline Percentage of Hb decrement (\%), median [IQR] & $12.6[7.0,17.5]$ & $5.9[-1.7,11.9]$ & $<0.001$ \\
\hline
\end{tabular}

If not indicated otherwise: $\mathrm{n}(\%)$

described in detail in Table 1. The PEGF group comprised 68 DGF and 30 SGF patients. Almost all recipient related parameters were similar between the groups, including baseline pre-transplant hemoglobin and postoperative hemoglobin. Differences were the cause of end-stage renal disease (ESRD), recipient baseline creatinine, and pre-transplant PRA. In contrast, almost all variables of donor and intraoperative factors had statistical difference between PEGF and IGF groups (as shown in Table 1). The estimated blood loss (EBL) in the PEGF group was significantly greater than in the IGF group $(400[300,600]$ vs. $300[200,400] \mathrm{mL} ; p<0.001)$, whereas both groups received intraoperative blood transfusions comparably (10.2 vs. $13.5 \%$; $p=0.435)$. Note that the need for 
vasopressor (a reflective indicator of perioperative hypotension) had no statistically different between groups. All variables with statistically significant between IGF and PEGF groups were submitted into logistic regression analysis. Although WIT was not significant in univariate analysis, this variable was also included into multivariate analysis because of its potential influence on perioperative $\mathrm{Hb}$ changes and being the risk of PEGF in the previous study [13].

The change (decrease) of $\mathrm{Hb}$ in patients with PEGF was significantly more pronounced as in patients with IGF $(-1.60[-2.38,0.83]$ vs. $-0.70[-1.35,0.20] \mathrm{g} / \mathrm{dL}$; $p<0.001$ ) (Additional file 2: Figure S2A). The percentage of $\mathrm{Hb}$ decrement, which covered the confounding effect of anemic/non-anemic $\mathrm{Hb}$ change, exhibited a similar result $(12.6[7.0,17.5]$ vs. $5.9[-1.7,11.9] \%$; $\mathrm{p}<0.001)$ (Additional file 2: Figure S2B). ROC curves were generated to define the optimal cut-points of both $\mathrm{Hb}$ parameters (Additional file 3: Figure S3). Within a range of $75-80 \%$ specificity, the cut-point values of $-1.35 \mathrm{~g} / \mathrm{dL}$ perioperative $\mathrm{Hb}$ change and $12.5 \% \mathrm{Hb}$ decrement provided better sensitivity and AUC than the others (Additional file 4: Table S1; full details in Additional file 5: Table S2). These cut-points were therefore applied for further association analysis. Note that pre-transplant and postoperative hemoglobin levels as simple variables were excluded from univariate analysis due to their limited performances in ROC analysis (Additional file 3: Figure S3).

Univariate analysis showed nearly all evaluated variables were significantly associated with PEGF, including a decremental change in perioperative $\mathrm{Hb}>1.35 \mathrm{~g} / \mathrm{dL}$ (crude OR $=3.62,95 \%$ CI 2.13-6.14; $p<0.001$ ) and the percentage of $\mathrm{Hb}$ decrement $>12.5 \%$ (crude $\mathrm{OR}=3.33$, $95 \%$ CI $1.97-5.65 ; p<0.001$ ) (Table 2). Since both parameters exhibited an excellent correlation (Additional file 2: Figure S2C), the stronger predictor from univariate analysis (perioperative $\mathrm{Hb}$ decrement $>1.35 \mathrm{~g} / \mathrm{dL}$ ) was served as the representative for further evaluation by multivariate analysis. All significant variables from univariate analysis were submitted to multivariate analysis to estimated their association with PEGF and also weigh the influence of perioperative $\mathrm{Hb}$. Multivariate analysis showed perioperative $\mathrm{Hb}$ decrement $>1.35 \mathrm{~g} / \mathrm{dL}$ was an independent risk of PEGF (adjusted OR $=2.52$, 95\% CI 1.11-5.72; $p=0.026$ ) (Table 3). Of other significant variables from univariate analysis, only CIT was proved as the risk of PEGF by multivariate analysis (adjusted $\mathrm{OR}=9.77$, 95\%CI 1.58-60.54; $p=0.014$ ) (Table 3).

Although donor type (deceased donor vs. living donor) was not statistically associated with PEGF in multivariate analysis, differences in donor physiology should still be taken into consideration. Subgroup
Table 2 Univariate analysis to identify the candidate risks of PEGF

\begin{tabular}{|c|c|c|c|c|}
\hline Variables & PEGF n (\%) & IGF $n(\%)$ & Crude OR $(95 \% \mathrm{Cl})$ & $P$-value \\
\hline \multicolumn{5}{|c|}{ Cause of ESRD } \\
\hline Unknown & $70(71.4)$ & $91(53.2)$ & $2.19(1.29-3.74)$ & 0.004 \\
\hline Known & $28(28.6)$ & $80(46.8)$ & & \\
\hline \multicolumn{5}{|c|}{ Recipient baseline creatinine (mg/dL) } \\
\hline$>8.5$ & $54(56.8)$ & $64(39.0)$ & $2.06(1.23-3.44)$ & 0.007 \\
\hline$\leq 8.5$ & $41(43.2)$ & $100(60.9)$ & & \\
\hline \multicolumn{5}{|c|}{ Pretransplant PRA (\%) } \\
\hline$>50$ & $24(25.0)$ & $15(8.9)$ & $3.4(1.68-6.87)$ & $<0.001$ \\
\hline$\leq 50$ & $72(75.0)$ & $153(91.1)$ & & \\
\hline \multicolumn{5}{|l|}{ Donor type } \\
\hline Deceased & $87(88.8)$ & $39(22.8)$ & $26.77(13.33-56.65)$ & $<0.001$ \\
\hline Living & $11(11.2)$ & $132(77.2)$ & & \\
\hline \multicolumn{5}{|c|}{ Donor age (year) } \\
\hline$>55$ & $21(21.9)$ & $13(7.8)$ & $3.29(1.57-6.94)$ & 0.002 \\
\hline$\leq 55$ & $75(78.1)$ & $153(92.2)$ & & \\
\hline \multicolumn{5}{|c|}{ Donor gender } \\
\hline Female & $22(22.4)$ & $88(51.5)$ & $0.27(0.15-0.47)$ & $<0.001$ \\
\hline Male & $76(77.6)$ & $83(48.5)$ & & \\
\hline \multicolumn{5}{|c|}{$\mathrm{HLA}-\mathrm{A}+\mathrm{B}+\mathrm{DR}$ mismatch } \\
\hline$>2$ & $75(76.5)$ & $144(84.2)$ & $0.61(0.33-1.14)$ & 0.143 \\
\hline$\leq 2$ & $23(13.5)$ & $27(15.8)$ & & \\
\hline \multicolumn{5}{|l|}{ WIT (min) } \\
\hline$>45$ & $42(43.8)$ & $54(32.5)$ & $1.59(0.95-2.68)$ & 0.084 \\
\hline$\leq 45$ & $54(56.3)$ & $111(66.8)$ & & \\
\hline \multicolumn{5}{|l|}{$\mathrm{CIT}(\mathrm{h})$} \\
\hline$>12$ & $84(85.7)$ & $33(19.3)$ & $25.09(13.44-53.09)$ & $<0.001$ \\
\hline$\leq 12$ & $14(14.3)$ & $138(80.7)$ & & \\
\hline \multicolumn{5}{|l|}{$\mathrm{EBL}(\mathrm{mL})$} \\
\hline$>500$ & $28(28.6)$ & $23(13.5)$ & $2.57(1.38-4.79)$ & 0.003 \\
\hline$\leq 500$ & $70(71.4)$ & $148(86.5)$ & & \\
\hline \multicolumn{5}{|c|}{ Perioperative Hb decrement (g/dL) } \\
\hline$>1.35$ & $53(54.1)$ & $42(24.6)$ & $3.62(2.13-6.14)$ & $<0.001$ \\
\hline$\leq 1.35$ & $45(45.9)$ & $129(75.4)$ & & \\
\hline \multicolumn{5}{|c|}{ Percentage of Hb decrement (\%) } \\
\hline$>12.50$ & $51(52.0)$ & $42(24.6)$ & $3.33(1.97-5.65)$ & $<0.001$ \\
\hline$\leq 12.50$ & $47(48.0)$ & $129(75.4)$ & & \\
\hline
\end{tabular}

analysis was therefore performed to elucidate the influence of perioperative $\mathrm{Hb}$ decrement on PEGF based upon donor types. The result showed perioperative $\mathrm{Hb}$ decrement $>1.35 \mathrm{~g} / \mathrm{dL}$ was the risk of PEGF in deceased donor (adjusted OR $=2.89,95 \%$ CI 1.11-7.55; $p=0.029$ ), but not in living donor (adjusted $\mathrm{OR}=1.68$, 95\% CI 0.23-12.15; $p=0.606$ ) (Table 3). Of note, the dataset used for univariate and multivariate analyses was provided in Additional file 6: Table S3. Lastly, the dose-effect relationship of perioperative $\mathrm{Hb}$ decrement 
Table 3 Multivariate analysis to identify PEGF-associated factors

\begin{tabular}{|c|c|c|c|c|c|c|}
\hline \multirow[t]{2}{*}{ Variables } & \multicolumn{2}{|l|}{ Whole cohort $(n=269)$} & \multicolumn{2}{|c|}{ Deceased donor $(n=126)$} & \multicolumn{2}{|l|}{ Living donor $(n=143)$} \\
\hline & Adjusted OR $(95 \% \mathrm{Cl})$ & $P$-value & Adjusted OR $(95 \% \mathrm{Cl})$ & $P$-value & Adjusted OR (95\% Cl) & $P$-value \\
\hline Unknown cause of ESRD & $1.84(0.81-4.19)$ & 0.148 & $1.85(0.68-4.98)$ & 0.227 & $1.30(0.25-6.82)$ & 0.753 \\
\hline Recipient baseline creatinine $>8.5 \mathrm{mg} / \mathrm{dL}$ & $1.83(0.83-4.03)$ & 0.135 & $1.57(0.61-4.05)$ & 0.349 & $3.18(0.64-15.77)$ & 0.157 \\
\hline Pretransplant PRA $>50 \%$ & $1.77(0.62-5.07)$ & 0.288 & $1.79(0.55-5.83)$ & 0.332 & $3.55(0.27-46.51)$ & 0.335 \\
\hline Deceased donor type & $2.96(0.41-21.37)$ & 0.282 & nd & nd & nd & nd \\
\hline Donor age $>55$ years & $1.37(0.45-4.20)$ & 0.538 & $1.61(0.46-5.62)$ & 0.452 & nd & nd \\
\hline Female donor & $0.89(0.35-2.23)$ & 0.798 & $1.03(0.31-3.42)$ & 0.968 & $0.47(0.09-2.37)$ & 0.359 \\
\hline $\mathrm{WIT}>45 \mathrm{~min}$ & $0.77(0.35-1.69)$ & 0.798 & $1.06(0.42-2.69)$ & 0.897 & $0.18(0.01-2.37)$ & 0.176 \\
\hline $\mathrm{CIT}>12 \mathrm{~h}$ & $9.77(1.58-60.54)$ & 0.014 & $11.49(1.89-69.77)$ & 0.008 & nd & nd \\
\hline $\mathrm{EBL}>500 \mathrm{~mL}$ & $1.71(0.65-4.49)$ & 0.276 & $1.73(0.54-5.59)$ & 0.360 & $2.86(0.41-19.95)$ & 0.289 \\
\hline Perioperative $\mathrm{Hb}$ decrement $>1.35 \mathrm{~g} / \mathrm{dL}$ & $2.52(1.11-5.72)$ & 0.026 & $2.89(1.11-7.55)$ & 0.029 & $1.68(0.23-12.15)$ & 0.606 \\
\hline
\end{tabular}

nd no data and not applicable

on the occurrence of PEGF in DDKT patients was demonstrated in Additional file 7: Figure S4.

\section{Discussion}

This study demonstrated that decremental change in perioperative $\mathrm{Hb}$ greater than $1.35 \mathrm{~g} / \mathrm{dL}$ served as an independent risk of PEGF development in deceased donor kidney transplantation, but not living donors. Deceased donor kidney grafts, which had prolonged ischemic injury, were apparently more vulnerable to changes of hemoglobin levels than kidneys from living donors. Reduction of hemoglobin at a significant level may reduce oxygen delivery to glomeruli and renal tubules, subsequently aggravate graft function impairment in deceased donor kidney transplant. Changes in $\mathrm{Hb}$ may represent perioperative insult, particularly intraoperative bleeding in conjunction with hemodilution due to excessive intravenous fluid administration. Our findings support the hypothesis of Guedes-Marques, et al. [18], that perioperative changes in hemoglobin concentration may serve as a novel modifiable factor of PEGF in patients undergoing deceased donor kidney transplant.

Several known risk factors of DGF were re-evaluated to clarify their association with PEGF in our study. As expected, CIT was confirmed as the strongest risk of PEGF. Deceased donor type was usually collinear with CIT. It was not surprising that deceased donor type failed to show association with PEGF in multivariate analysis, where CIT had the strongest influence. The previously identified risks of DGF (i.e., older donor, female donor, and higher PRA) [2-4, 15], and PEGF (i.e., recipient BMI, pre-transplant dialysis, and prolonged WIT) $[13,14]$ were not statistically confirmed as PEGF-associated factors when multivariate analysis was applied, probably due to the relative small sample size, or their associations were negated under the strong influence of CIT and/or perioperative $\mathrm{Hb}$ decrement.

The advantage of blood transfusion has to be weighted with its adverse reactions. The goal of blood transfusion is to maintain adequate oxygen delivery to tissue. Currently, the optimal point is still controversial, especially in ESRD patients who have variations in baseline hemoglobin and compensation mechanism. Many studies emphasized the risk of blood transfusion in kidney transplant patients, particularly allosensitization [19]. Meticulous surgical hemostasis and appropriate perioperative measures to lessen blood loss are the most appropriate approach to prevent perioperative $\mathrm{Hb}$ decrement. Nonetheless, in the situation that blood transfusion is unavoidable, our data suggested a target hemoglobin level should be raised within $0-1.35 \mathrm{~g} /$ $\mathrm{dL}$ of pre-operative hemoglobin levels. These practices might be benefits to reduce PEGF incidence and improve long-term graft outcomes. Further prospective study is undoubtedly required to prove this hypothesis.

\section{Limitations}

Several limitations included the lack of external validation, the small sample size, and the possible omission of confounders. The selected cut-off was based on the clinical intuition, while a data-driven estimation of the cut-off e.g., Youden-index might provide the better cutoff. Variations in treatment protocols i.e., the threshold for blood transfusion, accepted blood pressure and/ or surgical technique might affect the outcomes. Also, there were several missing data due to retrospective nature of the study. Finally, long-term graft outcome was not evaluated in this study. 


\section{Supplementary information}

Supplementary information accompanies this paper at https://doi. org/10.1186/s13104-020-05262-4.

Additional file 1: Figure S1. A flow chart describing the data collection procedure based on inclusion and exclusion criteria, and the excluded patient due to missing data.

Additional file 2: Figure S2. Comparison between patients with poor early graft function (PEGF; $n=98$ ) and immediate graft function (IGF; $n=171)$. A. Perioperative hemoglobin change was defined by the difference between post-operative and pre-operative hemoglobin concentrations (details in "Materials and Methods" section). B. The percentage of hemoglobin decrement was calculated by $100^{*}$ [pre-transplant hemoglobin - postoperative hemoglobin]/pre-transplant hemoglobin. C. A scatter plot showed a linear correlation between both parameters. The dashed blue line represented the selected cut-points based on Receiver Operating Characteristics (as shown in Table S1). Red color dots represent patients with PEGF, whereas grey color dots represent patients with IGF. Visually, both hemoglobin decrement measures associated with an increasing trend of PEGF. Data were presented as median and interquartile range [IQR]. $P$-value $<0.05$ was considered as statistically significant.

Additional file 3: Figure S3. The area under the ROC curve of various $\mathrm{Hb}$ parameters. The selected cut-off values for each $\mathrm{Hb}$ parameter which produced the specificity of $75-80 \%$ were shown in Table S1, while the full range of the sensitivity and specificity of all thresholds were provided in Table S2.

Additional file 4: Table S1. Area under the curve (AUC), sensitivity and specificity of the selected cut-point of perioperative $\mathrm{Hb}$ change, the percentage of $\mathrm{Hb}$ decrement, baseline pre-transplant hemoglobin and postoperative hemoglobin levels.

Additional file 5: Table S2. Sensitivities and specificities of all threshold of various $\mathrm{Hb}$ parameters including perioperative $\mathrm{Hb}$ change, the percentage of $\mathrm{Hb}$ decrement, baseline pre-transplant hemoglobin and postoperative hemoglobin levels.

Additional file 6: Table S3. The dataset used for univariate and multivariate analyses ( $n=269$ samples).

Additional file 7: Figure S4. The dose-effect relationship of perioperative $\mathrm{Hb}$ decrement on the occurrence of PEGF in DDKT patients $(n=126)$. The influence of perioperative $\mathrm{Hb}$ decrement, at each cut-off, was adjusted by the cause of ESRD, recipient baseline creatinine, Pretransplant PRA, donor age, donor gender, WIT, CIT and EBL as presented in Table 3.

\section{Abbreviations}

Hb: Hemoglobin; CIT: Cold ischemic time; DDKT: Deceased donor kidney transplant; DGF: Delayed graft function; EBL: Estimated blood loss; ESRD: Endstage renal disease; IGF: Immediate graft function; IQR: Interquartile range; LDKT: Living donor kidney transplantation; PEGF: Poor early graft function; PRA: Panel reactive antibody level; ROC: Receiver operating characteristic; SGF: Slow graft function; WIT: Warm ischemic time.

\section{Acknowledgements}

We greatly appreciated Professor Benno von Bormann for his proof reading and criticizing the original draft. We would like to thank all staffs in Ramathibodi Hospital's Kidney Transplant Project, Ramathibodi Hospital for their assistance, and also thank to Umaporn Udomsubpayakul for her statistical consultation. SC was financially supported for research activities by Faculty Staff Development Program of Faculty of Medicine Ramathibodi Hospital, Mahidol University, Thailand.

\section{Authors' contributions}

AC and SC participated in research design. AC, SC and AK participated in data collection, and the writing of the manuscript. AC, SC and Al participated in statistical analysis. Al, SK, VS, SiJ, and SoJ participated in revising the manuscript for intellectual content and contributed to overall research strategy. SC finalized the manuscript. All authors read and approved the final manuscript.

\section{Funding}

This study was supported by Talent Management Program of Mahidol University (TM:CP131 to AC).

\section{Availability of data and materials}

The dataset used or analysed during this study are included in this published article and its supplementary information files.

\section{Author details}

${ }^{1}$ Department of Anesthesiology, Faculty of Medicine Ramathibodi Hospital, Mahidol University, Bangkok, Thailand. ${ }^{2}$ Department for Clinical Epidemiology and Biostatistics, Faculty of Medicine Ramathibodi Hospital, Mahidol University, Bangkok, Thailand. ${ }^{3}$ Division of Nephrology, Department of Medicine, Faculty of Medicine Ramathibodi Hospital, Mahidol University, Bangkok, Thailand. ${ }^{4}$ Excellence Center of Organ Transplantation, Faculty of Medicine Ramathibodi Hospital, Mahidol University, Bangkok, Thailand. ${ }^{5}$ Division of Vascular and Organ Transplant Surgery, Department of Surgery, Faculty of Medicine Ramathibodi Hospital, Mahidol University, Bangkok, Thailand. ${ }^{6}$ Pediatric Translational Research Unit, Department of Pediatrics, Faculty of Medicine Ramathibodi Hospital, Mahidol University, 270 Rama VI Rd, Ratchathewi, Bangkok 10400, Thailand.

Received: 22 June 2020 Accepted: 28 August 2020

Published online: 05 September 2020

\section{References}

1. Nicholson ML, Wheatley TJ, Horsburgh T, Edwards CM, Veitch PS, Bell PR. The relative influence of delayed graft function and acute rejection on renal transplant survival. Transpl Int. 1996;9(4):415.

2. Halloran PF, Hunsicker LG. Delayed graft function: state of the art, November 10-11, 2000. Summit meeting, Scottsdale, Arizona, USA. Am J Transpl. 2001;1(2):115.

3. Perico N, Cattaneo D, Sayegh MH, Remuzzi G. Delayed graft function in kidney transplantation. Lancet. 2004;364(9447):1814.

4. Siedlecki A, Irish W, Brennan DC. Delayed graft function in the kidney transplant. Am J Transplant. 2011;11(11):2279.

5. de Sandes-Freitas TV, Felipe CR, Aguiar WF, Cristelli MP, Tedesco-Silva $\mathrm{H}$, Medina-Pestana JO. Prolonged delayed graft function is associated with inferior patient and kidney allograft survivals. PLOS ONE. 2015:10(12):e0144188.

6. Legendre C, Canaud G, Martinez F. Factors influencing long-term outcome after kidney transplantation. Transpl Int. 2014;27(1):19.

7. Fonseca I, Teixeira L, Malheiro J, Martins LS, Dias L, Castro Henriques A, et al. The effect of delayed graft function on graft and patient survival in kidney transplantation: an approach using competing events analysis. Transpl Int. 2015;28(6):738.

8. Yarlagadda SG, Coca SG, Garg AX, Doshi M, Poggio E, Marcus RJ, et al. Marked variation in the definition and diagnosis of delayed graft function: a systematic review. Nephrol Dial Transpl. 2008;23(9):2995.

9. Humar A, Johnson EM, Payne WD, Wrenshall L, Sutherland DE, Najarian JS, et al. Effect of initial slow graft function on renal allograft rejection and survival. Clin Transpl. 1997;11(6):623.

10. Humar A, Ramcharan T, Kandaswamy R, Gillingham K, Payne WD, Matas AJ. Risk factors for slow graft function after kidney transplants: a multivariate analysis. Clin Transpl. 2002;16(6):425.

11. Rodrigo E, Fernandez-Fresnedo G, Ruiz JC, Pinera C, Palomar R, GonzalezCotorruelo J, et al. Similar impact of slow and delayed graft function on renal allograft outcome and function. Transpl Proc. 2005;37(3):1431.

12. Nel D, Vogel J, Muller E, Barday Z, Kahn D. Slow early graft function: a neglected entity after renal transplantation. Nephron Clin Pract. 2012;120(4):c200

13. Nogueira JM, Haririan A, Jacobs SC, Weir MR, Hurley HA, Al-Qudah HS, et al. The detrimental effect of poor early graft function after laparoscopic live donor nephrectomy on graft outcomes. Am J Transpl. 2009;9(2):337.

14. Hellegering J, Visser J, Kloke HJ, D'Ancona FC, Hoitsma AJ, van der Vliet JA, et al. Poor early graft function impairs long-term outcome in living donor kidney transplantation. World J Urol. 2013;31(4):901. 
15. Ojo AO, Wolfe RA, Held PJ, Port FK, Schmouder RL. Delayed graft function: risk factors and implications for renal allograft survival. Transplantation. 1997;63(7):968.

16. Abou-Jaoude MM, Nawfal N, Najm R, Honeidi M, Shaheen J, Almawi WY. Effect of pretransplantation hemoglobin blood concentration on renal allograft survival and function. Transpl Proc. 2010;42(3):760.

17. Walsh M, Garg AX, Devereaux PJ, Argalious M, Honar H, Sessler DI. The association between perioperative hemoglobin and acute kidney injury in patients having noncardiac surgery. Anesth Analg. 2013;117(4):924.

18. Guedes-Marques M, Romaozinho C, Santos L, Macario F, Alves R, Mota A. Kidney transplantation: which variables should be improved? Transpl Proc. 2015;47(4):914.
19. Scornik JC, Bromberg JS, Norman DJ, Bhanderi M, Gitlin M, Petersen J. An update on the impact of pre-transplant transfusions and allosensitization on time to renal transplant and on allograft survival. BMC Nephrol. 2013;14:217.

\section{Publisher's Note}

Springer Nature remains neutral with regard to jurisdictional claims in published maps and institutional affiliations.
Ready to submit your research? Choose BMC and benefit from:

- fast, convenient online submission

- thorough peer review by experienced researchers in your field

- rapid publication on acceptance

- support for research data, including large and complex data types

- gold Open Access which fosters wider collaboration and increased citations

- maximum visibility for your research: over $100 \mathrm{M}$ website views per year

At BMC, research is always in progress.

Learn more biomedcentral.com/submissions 